\title{
Preparation and technical considerations for percutaneous cannulation for veno-arterial extracorporeal membrane oxygenation.
}

\author{
Kathleen Lamb \\ Thomas Jefferson University \\ Hitoshi Hirose \\ Thomas Jefferson University \\ Nicholas C. Cavarocchi \\ Jefferson College
}

Follow this and additional works at: https://jdc.jefferson.edu/surgeryfp

Part of the Surgery Commons

Let us know how access to this document benefits you

\section{Recommended Citation}

Lamb, Kathleen; Hirose, Hitoshi; and Cavarocchi, Nicholas C., "Preparation and technical considerations for percutaneous cannulation for veno-arterial extracorporeal membrane oxygenation." (2013). Department of Surgery Faculty Papers. Paper 108.

https://jdc.jefferson.edu/surgeryfp/108

This Article is brought to you for free and open access by the Jefferson Digital Commons. The Jefferson Digital Commons is a service of Thomas Jefferson University's Center for Teaching and Learning (CTL). The Commons is a showcase for Jefferson books and journals, peer-reviewed scholarly publications, unique historical collections from the University archives, and teaching tools. The Jefferson Digital Commons allows researchers and interested readers anywhere in the world to learn about and keep up to date with Jefferson scholarship. This article has been accepted for inclusion in Department of Surgery Faculty Papers by an authorized administrator of the Jefferson Digital Commons. For more information, please contact: JeffersonDigitalCommons@jefferson.edu. 


\title{
Preparation and Technical Considerations for Percutaneous Cannulation for Veno-Arterial Extracorporeal Membrane Oxygenation
}

\author{
Kathleen M. Lamb, M.D., Hitoshi Hirose, M.D., and Nicholas C. Cavarocchi, M.D. \\ Department of Surgery, Thomas Jefferson University, Philadelphia, Pennsylvania
}

\begin{abstract}
Background: The most frequent limb complications from peripheral veno-arterial extracorporeal membrane oxygenation (VA-ECMO) are limb ischemia and localized bleeding. To minimize these risks, perfusion of the distal limb with peripheral percutaneous cannulation was done. Technique: Percutaneous cannulation with a distal perfusion port was performed in all patients. During the VA-ECMO, distal limb perfusion was monitored using near-infrared spectroscopy to assess tissue oxygenation. At the decannulation, patch angioplasty was performed to prevent the development of narrowing of the artery at the cannulation site. Conclusions: Using our standard technique, we have not experienced any limb loss related to ischemia or bleeding. doi: 10.1111/jocs.12058 (J Card Surg 2013;28:190-192)
\end{abstract}

We describe our experience with percutaneous femoral cannulation for veno-arterial (VA) extracorporeal membrane oxygenation circulation (ECMO) - both preparation for and the technical aspects of this procedure.

\section{TECHNICAL DESCRIPTION}

Percutaneous placement of femoral ECMO cannulas can be done at any bedside in the hospital, intensive care unit (ICU), emergency room, or catheterization lab, or intra-operatively. This procedure is best performed with two operators to control the cannulas and wires. Before the procedure begins, both an upper extremity central venous line and an arterial line must be inserted for monitoring. After antibiotic administration, sterile prep, and draping of entire body, placement of femoral catheters begins with percutaneous puncture of the femoral vein. Following Seldinger's technique, ${ }^{1,2}$ a flexible j-tip guidewire $(0.038$ inch $\times 210 \mathrm{~cm}$, Edwards Lifesciences LLC, Irvine, CA, USA) is advanced from the femoral vein into the inferior vena cava (IVC), directed toward the right atrium. The ipsilateral or

Conflicts of interest: The authors have no conflicts of interest to disclose.

Address for correspondence: Nicholas C. Cavarocchi, M.D., Department of Surgery, Thomas Jefferson University, 607 College Building, 1025 Walnut Street, Philadelphia, PA 19107. Fax: 215-955-6010; e-mail: Nicholas.Cavarocchi@jefferson.edu contralateral femoral artery is punctured, with wire advancement toward the aortic valve. The superficial femoral artery (SFA) is accessed with a 21 gauge micropuncture needle, followed by a 0.018 inch nitinol wire (Cook Medical, Bloomington, IN, USA), directed toward the foot, for distal perfusion catheter (DPC) placement (Cook Medical; Fig. 1). ${ }^{3}$ After wire placement, a 50007500 unit heparin bolus is administered to prevent thrombosis in the cannulas. Cannulas are pre-selected based on our experience and estimated patient sizes, as measurements of vessel diameters are not typically available. We attempt to use the largest cannula feasible to minimize hemolysis. We refer to the manufacturer pressure-flow curves for each cannula size. ${ }^{1}$

The ECMO venous cannula $(55 \mathrm{~cm}$ or $68 \mathrm{~cm}, 18-28$ French, bio-compatible polyurethane, heparin-bonded, Edwards Lifesciences LLC) is premeasured from the femoral insertion site to a few centimeters below the angle of Louis, approximating the mid-right atrium, the ideal location for the tip of a venous cannula. Dilators are serially placed over the venous guidewire until access is appropriately enlarged, followed by placement of the venous catheter over the wire. This is advanced till the cannula tip is in the superior vena cava near the right atrium (Fig. 2). The stylette and wire are removed and the end of cannula is clamped. Dilators are serially placed over the arterial guidewire, followed by advancement of the arterial cannula $(24 \mathrm{~cm}, 16-22$ French, OptiSite Arterial Cannula, Edwards Lifescience 


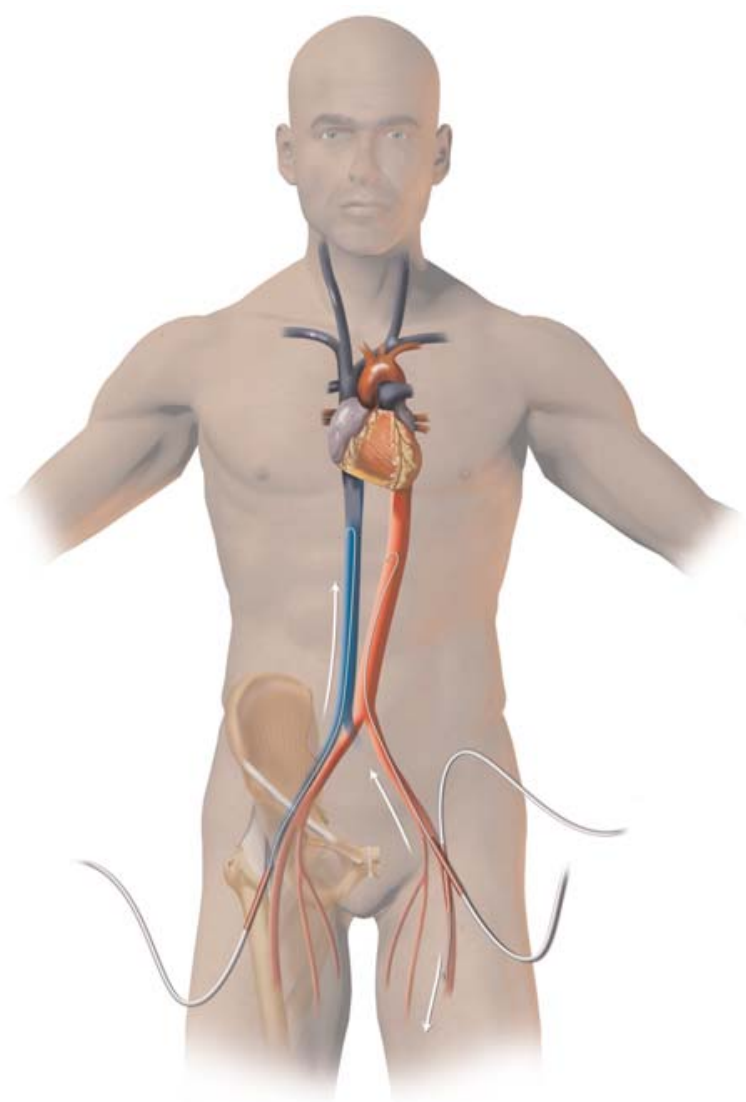

Figure 1. Percutaneous VA femoral ECMO guidewire access.

LLC) into the iliac artery. The stylette and wire are removed and end of the cannula clamped. A five or seven French DPC is placed over the SFA wire, after the arterial catheter placement. The venous line is de-aired and connected to the ECMO circuit. This is achieved by application of a steady stream of normal saline to fill the catheter, with forward flow of fluid from the circuit, displacing any air. The circuit involves a Rotaflow centrifugal pump (Maquet Cardiovascular LLC, San Jose, CA, USA), and a Quadrox-D diffusion membrane hollow-fiber oxygenator (Maquet Cardiovascular LLC). The arterial line is subsequently de-aired and connected. The arterial cannula side-port is connected with 6 inch extension tubing and a three-way stopcock to the DPC, de-aired, and opened to reestablish flow into the leg. It is imperative to examine the circuit for trapped air prior to starting the circuit. Upon completion, all clamps are removed; the patient is taken up to full flow of approximately $4-5 \mathrm{~L}$. The cannulas are secured to the skin with sutures. Pericannula bleeding can be addressed by placement of hemostatic pads. ${ }^{4}$

This procedure can usually be performed within 30 minutes, with blood loss of only 100cc; however, it is prudent to reserve two units of packed red blood cells. Prophylactic antibiotics are continued for 24 hours. Difficultly with cannulation seems related to preexisting peripheral vascular disease and overall small vessel caliber. ${ }^{2}$ We initially will attempt to use a smaller

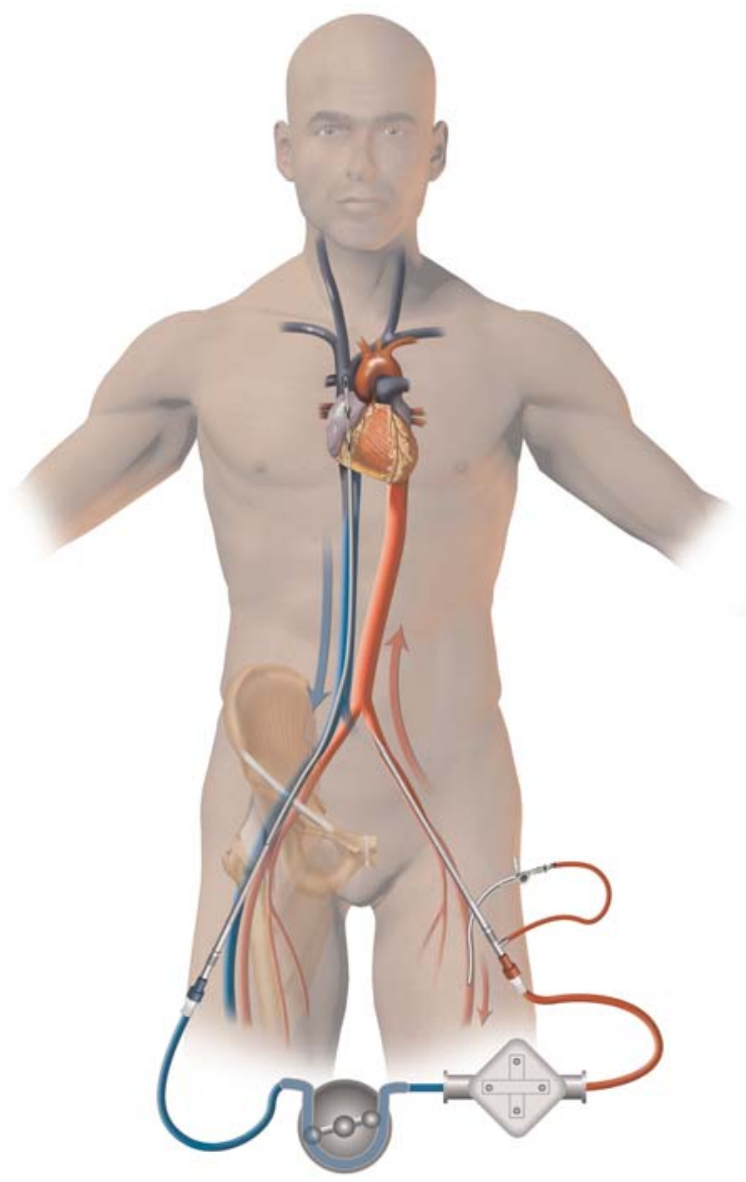

Figure 2. Percutaneous VA femoral ECMO cannulation.

size cannula. Fluoroscopy may be a necessary adjunct in these situations, rather than open cutdown, which leads to persistent pericannula hemorrhage.

Our heparin protocol involves administration of a bolus of 5000-7500 units after guidewire placement. Heparin is held for 24 hours unless clots are observed in the circuit. After 24 hours, an infusion is started with a prothrombin time (PTT) therapeutic goal of 40-45 seconds; from day 2 onward, PTT goal is 45-55 seconds. We prefer to use PTT to monitor anticoagulation as activated clotting time (ACT), although quick to obtain, is often unrealiable. We use heparin bonded circuitry and continuously monitor our ECMO circuitry and oxygenator for thrombi and change our system if inappropriate oxygenation.

Consistent with our attempts to maintain limb perfusion with DPC placement, the limb perfusion should be monitored continually using the near-infrared spectroscopy (NIRS). ${ }^{5}$ We are also able to monitor cerebral perfusion using NIRS to avoid cerebral ischemia allowing wider application of percutaneous femoral cannulation.

We recommend open repair when decannulating, as unexpected bleeding, hematoma, pseudoaneurysm or arteriovenous fistula may occur. This approach also allows bovine pericardial patching if it appears primary repair will lead to an area of stenosis. Prior to decannulation, heparin drip was continued until 
completion of repair of the vessels, avoiding cannula clot formation. The venous cannulation site is closed with purse string stitches, DPC site is closed primarily, while the arterial site often requires bovine patch angioplasty. Doppler examination and occasionally Fogarty thrombectomy are necessary.

\section{DISCUSSION}

There are a variety of benefits derived from percutaneous placement of ECMO cannulas including ease of placement at the bedside in the ICU. Due to heparinization while on ECMO, percutaneous access decreases hemorrhage associated with open cannulation, thus theoretically contributing to a decrease in overall morbidity. We try to avoid single groin cannulation, as in our experience bleeding complications tend to be higher with single groin cannulation. Cannulas in place for more than a few days leads to dilation of the arteriotomy and venotomy, leading to persistent pericannula hemorrhage and the need for ongoing transfusion. Percutaneous placement reduces this complication due to smaller arteriotomy/venotomy than with open techniques. At decannulation, open repair of the vessel prevents bleeding and hematoma development seen with percutaneous removal of catheters and subsequent hemostasis with manual pressure. Open repair of vessels also allows evaluation for potential areas of stenosis and ability to perform patch angioplasty if needed.

Cannulation-related complications can occur in approximately $5 \%$ to $8 \%$, in our experience of more than 100 percutaneous cannulations. These can include: local bleeding from the femoral puncture or distal perfusion cannula placement, dissection related with cannula advancement or the inability to pass the venous cannula due to clot formation from deep vein thrombosis. In these situations, the opposite groin can be accessed if necessary and bleeding controlled as described.

The most significant complication as the result of femoral cannulation is limb loss and ischemia. Preexisting peripheral vascular disease has been identified as a risk factor for development of ischemia in both percutaneous and open techniques. ${ }^{6}$ As such, known severe peripheral vascular disease is one of our only contraindications for femoral cannulation. Placement of DPC, NIRS monitoring, and patch closure of arteriotomy scan help prevent complications of limb ischemia.

\section{REFERENCES}

1. Pranikoff T, Hirschl RB, Remenapp R, et al: Venovenous extracorporeal life support via percutaneous cannulation in 94 patients. CHEST 1999;3:818-822.

2. Ganslmeier P, Philipp A, Repprecht L, et al: Percutaneous cannulation for extracoporeal life support. Thorac Cardiovasc Surg 2011;59:103-107.

3. Sidebotham D, McGeorge A, McGuinness S, et al: Emerging technology review: Extracoporeal membrane oxygenation for treating severe cardiac and respiratory failure in adults: Part 2 - Technical considerations. J Cardiothorac Vasc Anesth 2010;24(1):164-172.

4. Lamb KM, Pitcher HT, Cavarocchi NC, et al: Vascular site hemostasis in percutaneous extracorporeal membrane oxygenation therapy. Open Cardiovasc Thorac Surg J 2012;5:8-10.

5. Wong JK, Smith TN, Pitcher HT, et al: Cerebral and lower limb near-infared spectroscopy in adults on extracorporeal membrane oxygenation. Artif Organs 2012;36(8):659667.

6. Zimpfer D, Heinisch B, Czemy M, et al: Late vascular complications after extracorporeal membrane oxygenation support. Ann Thorac Surg 2006;81:892-895. 